\title{
Bilateral Facial Nerve Schwannoma: A Case Report and Review of the Literature
}

\author{
Kayvan Aghazadeh ${ }^{1}$, Benyamin Rahmaty ${ }^{2} \odot$, Ali Kouhi ${ }^{3}$, Sasan Dabiri ${ }^{4}$, Saeed Sohrabpour ${ }^{5}$, Maryam Mohammadzadeh ${ }^{6}$, \\ Neda Jafari ${ }^{7}$
}

\begin{abstract}
Aim and objective: To show a case with bilateral hemifacial spasm and bilateral facial nerve schwannoma (FNS) and explain few differential diagnoses for the facial nerve schwannomas, clinical presentation, genetic association, and their CT and MRI characteristics.

Background: Hemifacial spasm (HFS) is a hyperactive cranial neuropathy that causes paroxysmal facial muscle contraction. Bilateral hemifacial spasm (BHFS) is a very rare neurological syndrome whose diagnosis depends on excluding other facial dyskinesias. Facial nerve schwannoma (FNS) potentially affects any segment of the facial nerve (FN). Bilateral hemifacial spasm caused by bilateral FNS is a rare presentation also. Case description: The patient was a 39-year-old female with bilateral HFS and bilateral FNS. Grade II House-Brackmann Facial Nerve Grading System was observed on the right side of her face. Continuous facial tics were occurring during the examination on both sides of her face, particularly around the left eye. The patient was received bilateral injections of botulinum toxin $\mathrm{A}$. The patient underwent a scheduled close follow-up regarding hearing, facial nerve function, signs, and symptoms. In 1-month, 3-month, 6-month, and a year follow-ups, her symptoms were improved. We performed another MRI following a year, and the sizes of the lesions were equal as the first MRI. The patient was received bilateral injections of botulinum toxin A every 6 months. We decided to follow her up every 6 months for injection and every year by imaging. Conclusion: Surgery is a good option to remove the FNS, but close follow-up and symptomatic treatment, sometimes, are the best approaches when there are no significant facial nerve palsy and hearing loss.
\end{abstract}

Keywords: Bilateral hemifacial spasm, Botulinum toxin, Facial nerve schwannoma, Hemifacial spasm.

Otorhinolaryngology Clinics: An International Journal (2021): 10.5005/jp-journals-10003-1374

\section{BACKGROUND}

Facial nerve schwannoma (FNS), also known as facial nerve neurinoma/neurilemoma, arises from Schwann cells and originates from anywhere along the course of the facial nerve, from its origin in the cerebellopontine angle ( $\mathrm{CP}$ angle) to its extracranial branches in the parotid space. ${ }^{1-3}$ Facial nerve symptoms include mass effect on adjacent structures, which may result in sensory neural hearing loss, conductive hearing loss, middle ear mass, vestibular findings (oscillopsia, disequilibrium, and postural instability), and facial nerve dysfunction, which may vary from idiopathic Bell's palsy, weakness, focal twitch, and/or full hemifacial spasm. ${ }^{4}$

We herein present a case of bilateral facial nerve schwannoma with bilateral hemifacial spasm and provide an analysis of clinical presentations, MR and CT imaging findings.

\section{Case Description}

A 39-year-old woman presented with bilateral involuntary facial twitchings to our ENT clinic, which is a tertiary referral center. Her symptoms progressed gradually over 7 years. At the beginning, lower half of the right side of her face was involved, but eventually, it spreads to the upper part, with milder twitching and sudden muscle contractions particularly around the left eye for 6 months. Recently, the twitchings occur for a few seconds on both sides of her face that is asymmetric and asynchronous, which repeat over and over again 30-40 times every day on the right side and one time every week on the left side (Fig. 1 and Video 1). The patient had a bad experience last year due to paralysis of the right side of
${ }^{1-5}$ Department of Otorhinolaryngology Research Center, Amir Alam Hospital, Tehran University of Medical Sciences, Tehran, Iran

${ }^{6,7}$ Department of Radiology, Tehran University of Medical Sciences, Tehran, Iran

Corresponding Author: Benyamin Rahmaty, Department of Otorhinolaryngology Research Center, Amir Alam Hospital, Tehran University of Medical Sciences, Tehran, Iran, Phone: +989127253827, e-mail: Benyamin.Rahmaty@gmail.com

How to cite this article: Aghazadeh K, Rahmaty B, Kouhi A, et al. Bilateral Facial Nerve Schwannoma: A Case Report and Review of the Literature. Int J Otorhinolaryngol Clin 2021;13(2):47-52.

Source of support: Nil

Conflict of interest: None

her face and its inappropriate appearance with botulinum toxin therapy with no additional workup.

The patient was suffering from the buzzing in both ears and headache occasionally. There were no other complaints of visual defects, blurry vision, hearing loss, and other sensory discomforts and symptoms. She had fatty liver and mild hyperlipidemia in her past medical history. She was taking nortriptyline $10 \mathrm{mg} /$ day, clonazepam $1 \mathrm{mg} /$ day, escitalopram $10 \mathrm{mg} /$ day, propranolol $10 \mathrm{mg} / \mathrm{day}$, and buspirone $5 \mathrm{mg} /$ day a year ago for her anxiety and depression. She did not have a history of neurofibromatosis and other genetic disorders in her family; her son underwent surgery on June 15, 2013, and had 30

() The Author(s). 2021 Open Access This article is distributed under the terms of the Creative Commons Attribution 4.0 International License (https://creativecommons. org/licenses/by-nc/4.0/), which permits unrestricted use, distribution, and non-commercial reproduction in any medium, provided you give appropriate credit to the original author(s) and the source, provide a link to the Creative Commons license, and indicate if changes were made. The Creative Commons Public Domain Dedication waiver (http://creativecommons.org/publicdomain/zero/1.0/) applies to the data made available in this article, unless otherwise stated. 


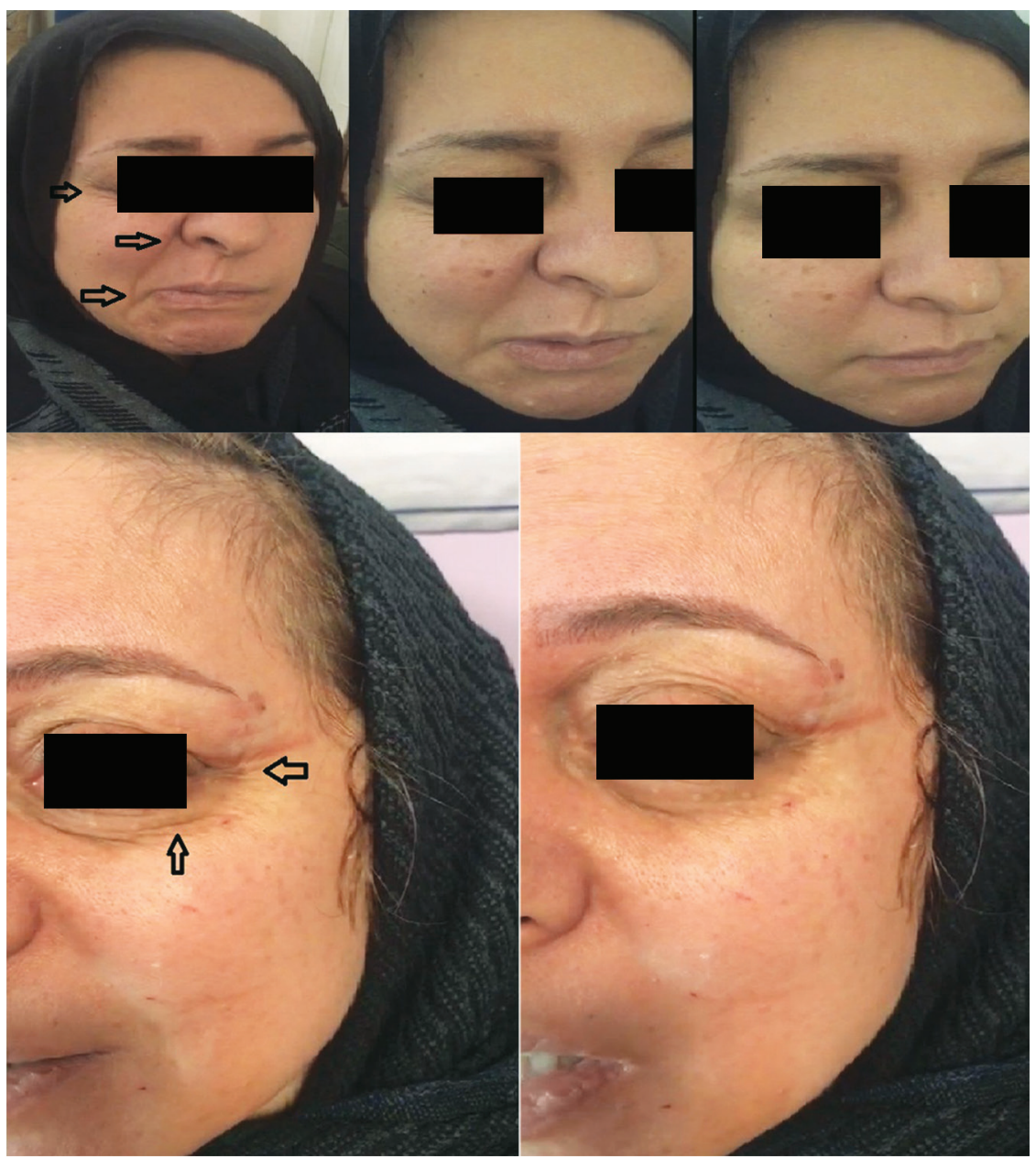

Fig. 1: Hemifacial spasm (HFS) on both sides of the face, on the right side, is severer than the left side

sessions of radiotherapy because of cerebellar medulloblastoma. The patient had a normal review of systems and vital signs. Multiple freckle-like pigmented macules were seen on the face, neck, and trunk but not over $5 \mathrm{~mm}$ in greatest diameter. A grade II-slight dysfunction_of the House- Brackmann Facial Nerve Grading System was observed on the right side of her face. Continuous facial tics were occurring during the examination on both sides of her face, particularly around the left eye. Both ears were normal with a microscope examination. Other examinations were unremarkable. The hearing was within normal limits on pure tone audiometry (Fig. 2). A diagnosis of bilateral facial schwannomas was made after studying CT findings (Fig. 3) and MRI findings (Fig. 4). The patient was received bilateral injections of botulinum toxin $A$. The doses we used were according to Table 1; this intervention improved her spasms and headache at 2 weeks follow-up. The patient underwent a scheduled close follow-up regarding hearing, facial nerve function, signs, and symptoms. In 1-month, 3-month, 6-month, and a year follow-ups, her symptoms were improved, and grade II House-Brackmann Facial Nerve Grading System was observed on both sides of her face also. We performed another MRI following a year, and the sizes of the lesions were equal as the first MRI. The patient was received bilateral injections of botulinum toxin A every 6 months.
We decided to follow her up every 6 months for injection and every year by imaging.

\section{Discussion}

Facial nerve schwannoma (FNS) represents less than $1 \%$ of temporal bone tumors. ${ }^{5}$ Schwannomas do not produce facial weakness until they become very large despite hemangiomas. Symptoms of IAC FNS are often related to the vestibulocochlear nerve such as hearing loss, disequilibrium, vertigo, and tinnitus rather than the facial nerve; complete facial nerve paralysis is uncommon. ${ }^{6}$ Sometimes, a facial nerve tic is evident, which helps distinguish facial neuromas from acoustic neuromas but not from primary cholesteatomas.

Carlson et al. ${ }^{7}$ in a large series analyzed 80 patients with FNS over 25 years. Moreover, $54 \%$ of patients presented with asymmetrical hearing loss, $41 \%$ reported facial paresis, and $26 \%$ reported facial spasm.

CT and MRI are the mainstays of diagnosis; intratemporal facial nerve lesions may produce bone destruction. CT cannot distinguish facial nerve neuromas from acoustic neuromas because of histological and same enhancement characteristics. Enlarging the geniculate ganglion and fallopian canal is common in distal tumors on $\mathrm{CT}^{8}$ 
Frequency in hertz

1252505007501000150020003000400080009000

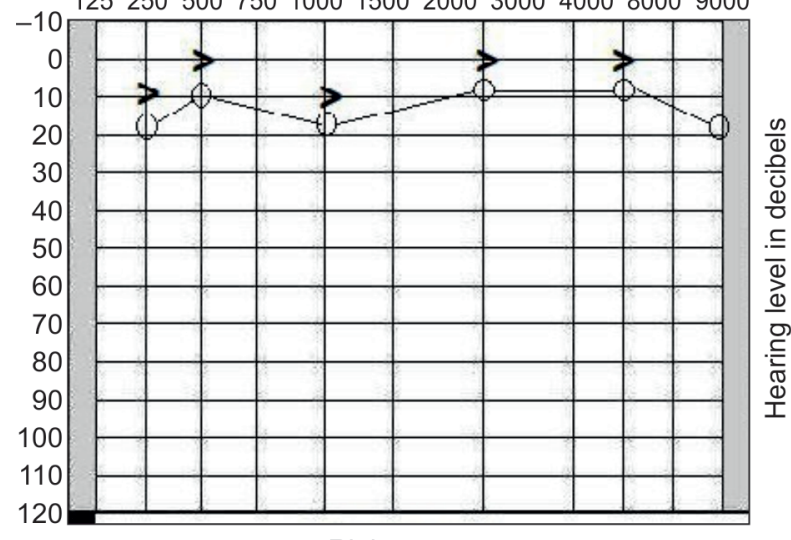

Right ear
Frequency in hertz

1252505007501000150020003000400080009000

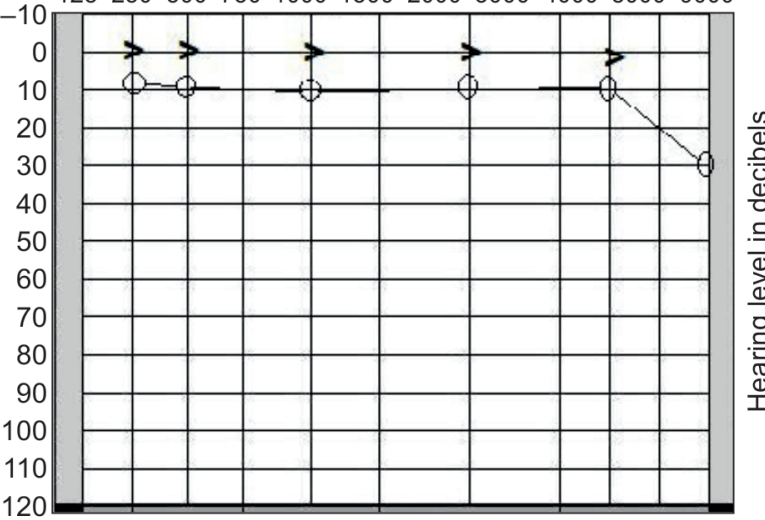

Left ear

Speech audiometry

\begin{tabular}{|l|l|l|l|l|l|l|l|l|}
\hline SRT & SM & WRS & HL & EM & WRS & HL/ & MCL & UCL \\
\hline SAT & & $100 \%$ & & & & 40 & \\
\hline 10 & & BHL & JB HL \\
\hline 10 & & $100 \%$ & & & & 10 & \\
\hline
\end{tabular}

\begin{tabular}{|c|c|c|c|c|c|c|c|}
\hline \multicolumn{10}{|c|}{ Acoustic reflex thresholds } \\
\hline \multicolumn{2}{|c|}{ Stimubis } & Measured & 500 & $1 \mathrm{~K}$ & $2 \mathrm{~K}$ & $4 \mathrm{~K}$ & Decay \\
\hline $\begin{array}{c}\text { Control } \\
\text { HL }\end{array}$ & RF & I.F. & NR & NR & NR & NR & \\
\hline $\begin{array}{c}\text { IP SI } \\
\text { HL }\end{array}$ & RE & RE & NR & NR & NR & NR & \\
\cline { 2 - 8 } & LE & 95 & 95 & 100 & 100 & \\
\hline
\end{tabular}

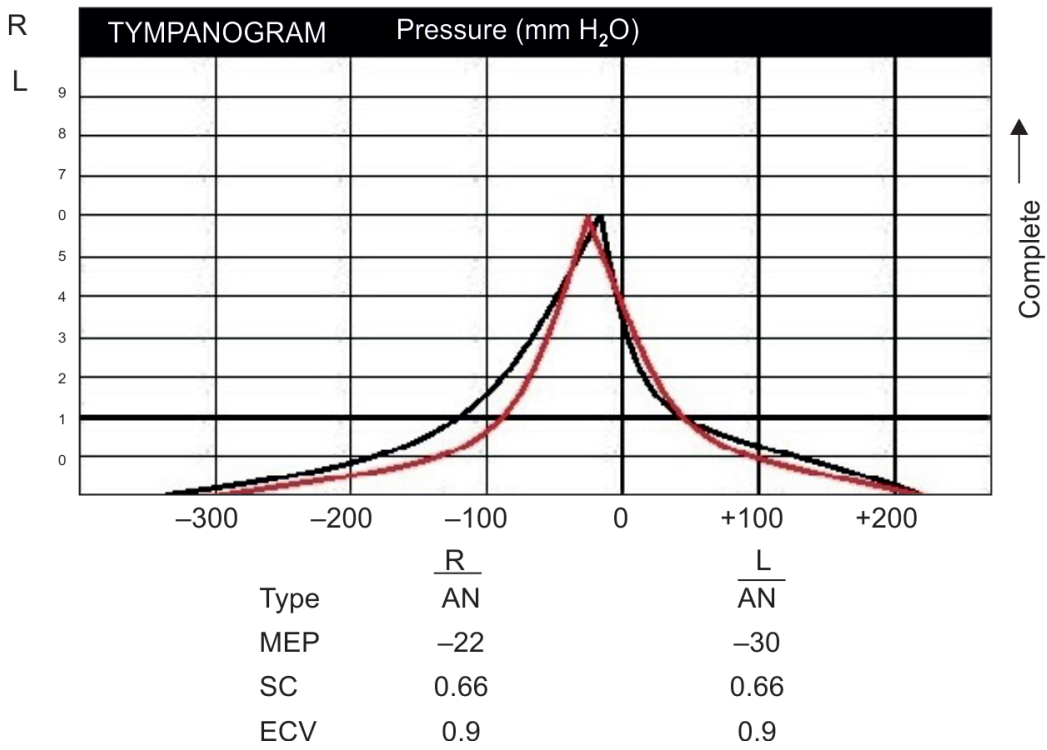

Fig. 2: It shows audiogram [pure tone audiogram; speech reception threshold; most comfortable level; and tympanogram; all parameters are normal]

Wiggins et al. ${ }^{4}$ described the most common location of the facial nerve schwannoma in the geniculate fossa (83\%), followed by the labyrinthine and tympanic segments of the facial nerve (both 54\%). The most common clinical presentation was facial neuropathy (42\%).

Lobulated enhancing mass that peripherally elevated signal ("target sign") on T2-weighted imaging ${ }^{9,10}$ and cystic change when the lesion is larger is helpful to discover FNS.

We did not use genetic testing to identify gene mutations associated with NF2; Symon et al. ${ }^{2}$ reported 12 cases of neuromas of the facial nerve; two patients had neurofibromatosis.
Fenton et al. ${ }^{11}$ in 1999 reported a case with imbalance and bilateral intracanalicular facial nerve schwannomas; the larger tumor was on the right side. Although we did not schedule surgery for our patient because of normal hearing and normal function of the facial nerve, their patient underwent surgery with mid-cranial fossa approach; postoperatively, the patient lost cochlear and facial function bilaterally. Genetic screening identified a mutation in the NF2 gene in their patient. Their conclusion was that the bilateral facial neuromas should be included in the clinical criteria for the neurofibromatosis type 2 . 


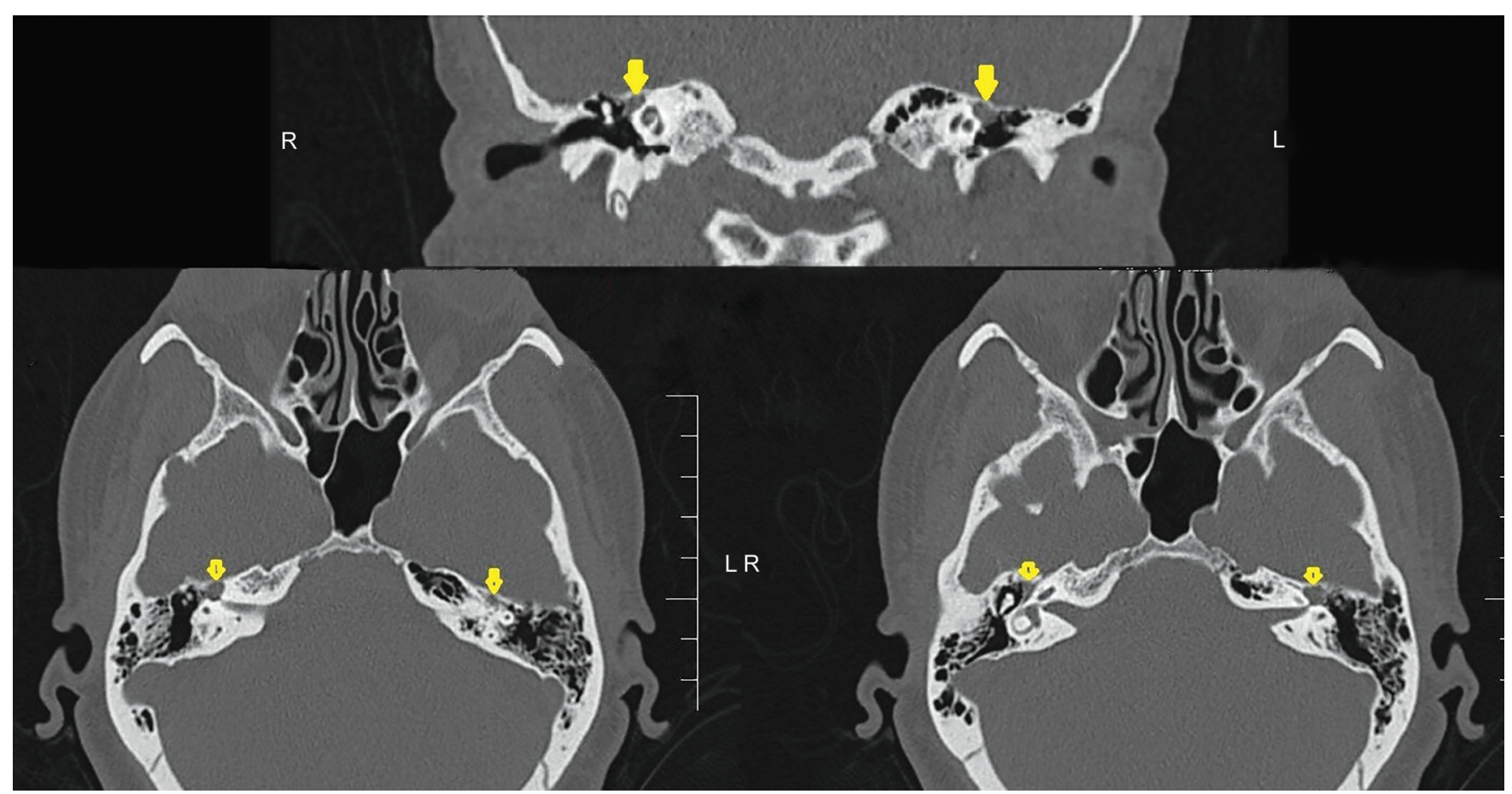

Fig. 3: Axial and coronal bone window HRCT of the temporal bone reveals two schwannomas in the geniculate ganglia on both sides. Note that the location of the lesions is above the cochlea on each side

Hemangiomas occur most often in the region of the geniculate ganglion (perigeniculate capillary plexus). ${ }^{8,12}$ Patients usually present with rapid onset of $\mathrm{SNHL}$, and disequilibrium or dizziness, mild facial weakness, and a decreased corneal reflex. ${ }^{13}$ Early progressive facial weakness despite the facial nerve neuromas is characteristic of hemangiomas. Irregular and indistinct bone margins and intratumoral bone spicules despite facial nerve schwannoma may be identified on CT and MR imaging. ${ }^{8,12,14}$ Bilateral hemangiomas are not reported yet.

Bilateral congenital cholesteatoma is a rare condition. There are a few studies ${ }^{15,16}$ that reported cases of bilateral congenital cholesteatoma. They may produce pressure on cranial nerves VII and VIII with continued growth. Facial nerve ischemia occurs when the cholesteatoma involves the geniculate ganglion. ${ }^{17}$

Facial twitching and progressive facial paralysis are more common with these lesions than with schwannomas. They have also irregular margins, inhomogeneous, and low signal to brain on T1-weighted images, and they are homogeneous and isointense or hyperintense to the brain on T2-weighted images and usually slightly brighter than CSF on MRI. Diffusion-weighted MRI is a technique for detecting cholesteatoma. 8,17

Peripheral nerve disorders such as cramps, neuromyotonia, tetany, and hemifacial spasm result in abnormal muscle movements. Hemifacial spasm is characterized by repetitive, involuntary contractions of the muscles supplied by facial (VII) nerve. Patterns of spasms are often around the orbicularis oculi and then spread to the cheek and levator anguli oris muscles. Voluntary activity may provoke contractions. Slight facial weakness may also be found on examination. Compressing the facial nerve may present with hemifacial spasm; ${ }^{18}$ other causes of primary hemifacial spasm (pHFS) include psychogenic spasm, tics, facial myokymia, or blepharospasm. ${ }^{19}$

Procedures such as injection of botulinum toxin A into the affected muscles and microvascular decompression (MVD) may suppress the contractions, although injection must be repeated every 3 or 4 months. $^{18}$

Xiao et al. ${ }^{20}$ treated 19 HFS patients with unilateral and 24 with bilateral BT therapy using botulinum toxin; bilateral BT therapy is better for HFS without producing additional adverse effects.

Although our patient had a bad experience with botulinum toxin therapy, we suggested that asymmetry with bilateral injections of BT is lower than unilateral injections. The patient received bilateral injections of botulinum toxin $A$. The doses we used were the same as Singh's study, ${ }_{1}^{10}$ and the dosage of Botox was according to Table 1; this intervention improved her symptoms. We decided to follow her up after the second MRI every 6 months for injection and every year by imaging.

\section{Conclusion}

Facial nerve schwannoma is a benign tumor, and its clinical presentation is associated with the tumor's location. Hemifacial spasm might be the only presentation of the tumor. Geniculate ganglion is the most common site as an origin of the tumor. Even though surgery is a good option to remove the tumor, close follow-up and symptomatic treatment, sometimes, are the best approaches when there is no hearing loss, and facial symptoms can be improved by medication. So, patients would not tolerate facial nerve palsy, deafness, and morbidities following surgery. 

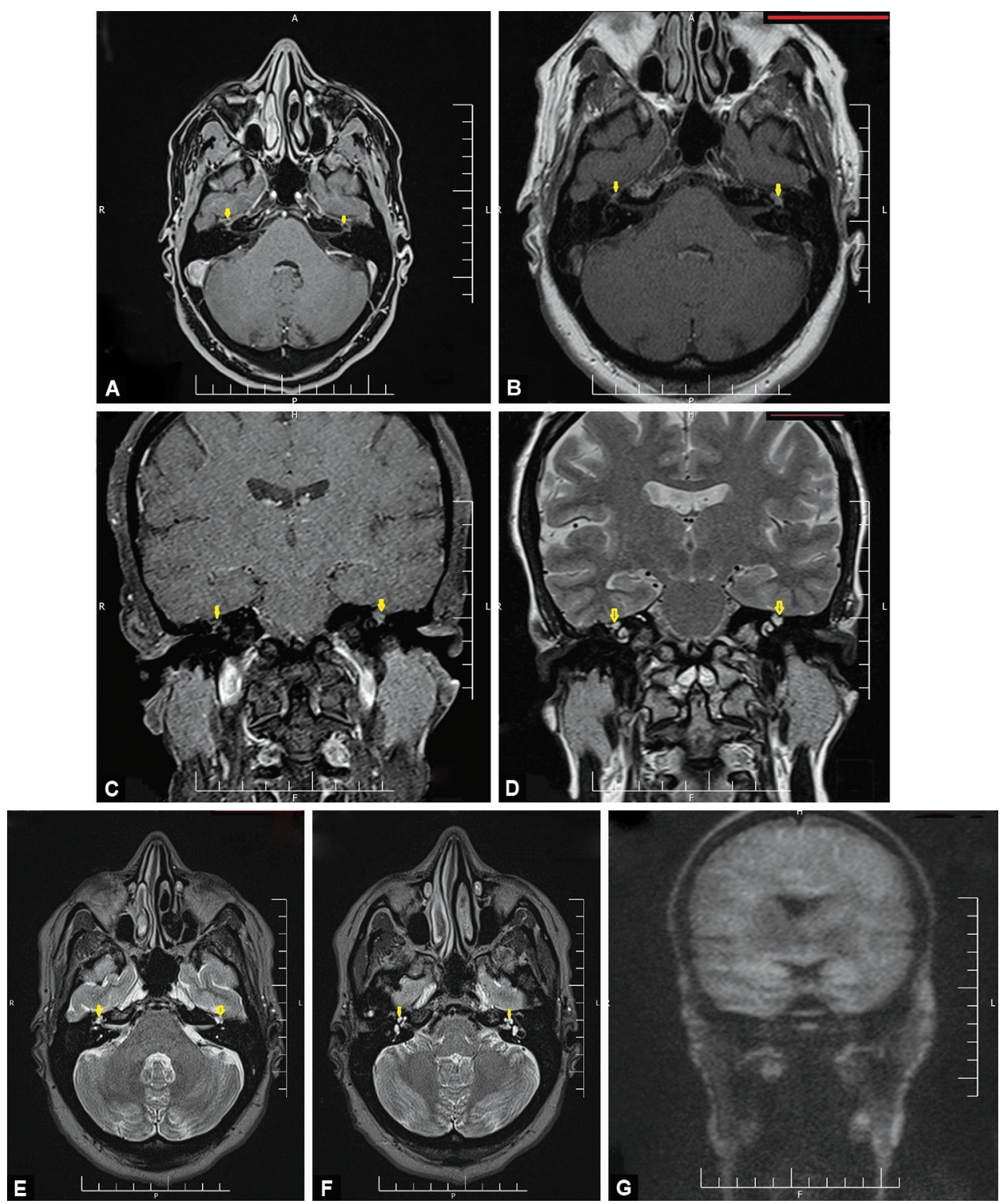

Figs 4A to G: (A and B) Axial contrast-enhanced T1-weighted magnetic resonance images that demonstrate enhancing masses behind the temporal lobes on both sides that involved the geniculate ganglions. Geniculate ganglia are enlarged on both sides. The mass is larger on the left side (as shown by the arrows). A coronal contrast-enhanced T1-weighted magnetic resonance image demonstrates enhancing masses that involved the geniculate ganglions on both sides (as shown by the arrow in C); and coronal T2-weighted magnetic resonance imaging reveals geniculate ganglion tumors on both sides (shown by the arrows in D); (E and F) Contrast-enhanced axial T2-weighted magnetic resonance images that reveal geniculate ganglion tumors on both sides (shown by the arrows). The tumors have higher signal intensity around the periphery on T2-weighted images (target sign); (G) It is a coronal DWI image that shows no restricted lesion; therefore, this particular setting rules out cholesteatoma

Table 1: Muscles and varied dosage of Botox in HFS

\begin{tabular}{lc}
\hline Frontalis muscle & 8 units \\
Procerus & 5 units \\
Upper eyelid orbicularis oculi injected at two sides & 2 units \\
Lower eyelid orbicularis oculi injected at two sides & 2 units \\
Lateral canthus & 6 units \\
Zygomaticus major & 2 units \\
Masseter injected at two sites & 25 units \\
Total & 50 units \\
\hline
\end{tabular}

\section{OrCID}

Benyamin Rahmaty $\odot$ https://orcid.org/0000-0003-1487-4385

\section{References}

1. O'Donoghue GM, Brackmann DE, House JW, et al. Neuromas of the facial nerve. Am J Otol 1989 Jan;10(1):49-54. PMID: 2719087.

2. Symon $L$, Cheesman $A D$, Kawauchi $M$, et al. Neuromas of the facial nerve: a report of 12 cases. Br J Neurosurg 1993;7(1):13-22. DOI: 10.3109/02688699308995051. 
3. Balle $\mathrm{VH}$, Greisen O. Neurilemmomas of the facial nerve presenting as parotid tumors. Ann Otol Rhinol Laryngol 1984;93(1):70-72. DOI: 10.1177/000348948409300116.

4. Wiggins RH, Harnsberger HR, Salzman KL, et al. The many faces of facial nerve schwannoma. AJNR Am J Neuroradiol 2006 Mar;27(3):694-9. PMID: 16552018; PMCID: PMC7976970.

5. Mundada P, Purohit BS, Kumar TS, et al. Imaging of facial nerve schwannomas: diagnostic pearls and potential pitfalls. Diagn Interv Radiol 2016;22(1):40-46. DOI: 10.5152/dir.2015.15060.

6. Dort JC, Fisch U. Facial nerve schwannomas. Skull Base 1991;1(01): 51-56. DOI: 10.1055/s-2008-1056979.

7. Carlson ML, Deep NL, Patel NS, et al. Facial nerve schwannomas: review of 80 cases over 25 years at Mayo Clinic. Mayo Clin Proc 2016;91(11):1563-1576. DOI: 10.1016/j.mayocp.2016.07.007.

8. Flint $P$, Haughey $B$, Lund V, et al. Otolaryngology-head and neck surgery. 6th ed. 2015.

9. Shimizu K, Iwai H, Ikeda K, et al. Intraparotid facial nerve schwannoma: a report of five cases and an analysis of MR imaging results. AJNR Am J Neuroradiol 2005 Jun-Jul;26(6):1328-30. PMID: 15956491; PMCID: PMC8149055.

10. Singh S. Botulinum toxin in hemifacial spasm: revisited. Indian J Plastic Surg 2013;46(1):159-160. DOI: 10.4103/0970-0358.113746.

11. Fenton JE, Morrin MM, Smail M, et al. Bilateral facial nerve schwannomas. Eur Arch Oto-Rhino-Laryngol 1999;256(3):133-135. DOI: $10.1007 / \mathrm{s} 004050050125$.
12. Touska P, Juliano AFY. Temporal bone tumors. Neuroimaging Clin $\mathrm{N}$ Am 2019;29(1):145-172. DOI: 10.1016/j.nic.2018.09.007.

13. Brackmann DE, Bartels LJ. Rare tumors of the cerebellopontine angle. Otolaryngol Head Neck Surg 1980;88(5):555-559. DOI: 10.1177/019459988008800508.

14. Kim M, Rowed DW, Cheung G, et al.Cavernous malformation presenting as an extra-axial cerebellopontine angle mass: case report. Neurosurgery 1997;40(1):187-190. DOI: 10.1097/00006123-199701000-00041.

15. Soldati D, Mudry A. Knowledge about cholesteatoma, from the first description to the modern histopathology. Otol Neurotol 2001;22(6):723-730. DOI: 10.1097/00129492-200111000-00003.

16. Fedok FG, Bellissimo JB, Wiegand DA. Bilateral congenital aural cholesteatoma. Otolaryngol Head Neck Surg 1990;103(6):1028-1030. DOI: $10.1177 / 019459989010300624$.

17. Axon PR, Fergie N, Saeed SR, et al. Petrosal cholesteatoma: management considerations for minimizing morbidity. Am J Otol 1999 Jul;20(4):505-10. PMID: 10431894.

18. Roger P. Simon MJA, Greenberg DA. Clinical neurology. 10th ed. The McGraw-Hill Companies; 2018.

19. Lefaucheur JP, Ben Daamer N, Sangla S, et al. Diagnosis of primary hemifacial spasm. Neurochirurgie 2018;64(2):82-86. DOI: 10.1016/j. neuchi.2017.12.003.

20. Xiao L, Pan L, Li B, et al. Botulinum toxin therapy of hemifacial spasm: bilateral injections can reduce facial asymmetry. J Neurol 2018;265(9):2097-2105. DOI: 10.1007/s00415-018-8960-2. 